\title{
Implementing a modified World Health Organization safe childbirth checklist in health centers of Ethiopia: a pre and post intervention study
}

Hailemariam Segni Abawollo* (D), Zergu Tafesse Tsegaye, Binyam Fekadu Desta, Tsega Teferi Mamo, Haregewoin Getachew Mamo, Zebyderu Tesfay Mehari, Zenawork Kassa Gebremedhin and Ismael Ali Beshir

\begin{abstract}
Background: Childbirth is a complex process, and checklists are useful tools to remember steps of such complex processes. The World Health Organization safe childbirth checklist is a tool used to improve the quality of care provided to women giving birth. The checklist was modified by Ministry of Health and was introduced to health centers in Ethiopia by the USAID Transform: Primary Health Care Activity.
\end{abstract}

Methods: A pre and post intervention study design with prospective data collection was employed. The availability of essential childbirth supplies and adherence of health care providers to essential birth practices were compared for the pre and post intervention periods.

Results: The pre and post intervention assessments were conducted in 247 and 187 health centers respectively. A statistically significant improvement from $63.6 \%$ pre intervention to $83.5 \%$ post intervention was observed in the availability of essential childbirth supplies, $\mathrm{t}(389.7)=-7.1, p=0.000$. Improvements in adherence of health care providers to essential birth practices were observed with the highest being at pause point three $(26.2 \%, \mathrm{t}(306.3)=$ $-10.6, p=0.000)$ followed by pause point four $(21.1 \%, \mathrm{t}(282.5)=-8.0, p=0.000)$, and pause point two $(18.2 \%, \mathrm{t}$ $(310.8)=-9.7, p=0.000)$. The least and statistically non-significant improvement was observed at pause point one $(3.3 \%, \mathrm{t}(432.0)=-1.5, p=0.131)$.

Conclusion: Improvement in availability of essential childbirth supplies and adherence of health care providers towards essential birth practices was observed after introduction of a modified World Health Organization safe childbirth checklist. Scale up of the use of the checklist is recommended.

Keywords: WHO safe childbirth checklist, Essential childbirth supplies, Essential childbirth practices, USAID transform: primary health care

\footnotetext{
* Correspondence: hailemariam_segni@et.jsi.com

JSI/Transform: Primary Health Care Activity, Addis Ababa, Ethiopia
}

(c) The Author(s). 2021 Open Access This article is licensed under a Creative Commons Attribution 4.0 International License, which permits use, sharing, adaptation, distribution and reproduction in any medium or format, as long as you give appropriate credit to the original author(s) and the source, provide a link to the Creative Commons licence, and indicate if changes were made. The images or other third party material in this article are included in the article's Creative Commons licence, unless indicated otherwise in a credit line to the material. If material is not included in the article's Creative Commons licence and your intended use is not permitted by statutory regulation or exceeds the permitted use, you will need to obtain permission directly from the copyright holder. To view a copy of this licence, visit http://creativecommons.org/licenses/by/4.0/. The Creative Commons Public Domain Dedication waiver (http://creativecommons.org/publicdomain/zero/1.0/) applies to the data made available in this article, unless otherwise stated in a credit line to the data. 


\section{Background}

Globally, maternal mortality is unacceptably high with the majority of the deaths being potentially preventable and occurring in low- and middle-income countries. Around 830 women die daily from pregnancy and childbirth related complications [1].

Since 1990 many sub-Saharan African countries have been successful in reducing their rates of maternal mortality. Sustainable Development Goal 3 includes a target that aims to reduce the global maternal mortality ratio to less than 70 per 100,000 live births, with no country having a maternal mortality rate of more than twice the global average [2, 3].

Around $75 \%$ of all maternal deaths are due to severe bleeding, infections, high blood pressure during pregnancy, complications from delivery, and unsafe abortions [4].

Maternal and newborn health are closely linked. Approximately 2.7 million newborn babies died in 2015, and an additional 2.6 million were stillborn. It is of paramount importance that all births are attended by skilled health professionals, as timely management can make the difference in the lives of both the mother and the baby $[5,6]$.

Childbirth is a complex process, and it is essential to remember to provide everything that is needed to ensure both the mother and newborn receive the safest care possible. Checklists are essential tools that organize such complex and important processes [7, 8]. The World Health Organization (WHO) safe childbirth checklist (SCC) is one of these tools, used to improve the quality of care provided to women during childbirth and in the hours afterwards. It is a well-organized list of evidence-based essential birth practices (EBPs) which focus on top causes of maternal deaths, intrapartum-related stillbirths, and early neonatal deaths [9].

In Namibia, the use of the WHO SCC showed an improvement in average EBPs delivered from 68 to $95 \%$ [10]. In Rajasthan, India, the use of the WHO SCC increased providers' performance of best practices, reflecting improvements in quality of facility childbirth care for women and newborns [11]. In Uttar Pradesh, India, birth attendants' adherence to EBPs was higher in facilities that used the coachingbased WHO SCC program than in those that did not [12]. In Aceh, Indonesia, use of the WHO SCC improved the quality of maternal care and overall birth experiences [13].

The WHO SCC was modified by Ministry of Health in Ethiopia and the USAID Transform: Primary Health Care Activity has introduced it to its catchment health centers and has carried out pre and post intervention assessment of changes.

\section{Methods}

Aim

The aim of this study was to assess pre and post intervention changes in availability of essential childbirth supplies and adherence of health care providers to EBPs.

\section{Design}

A health facility-based pre and post intervention study design with prospective data collection was employed to assess the changes pre and post the intervention.

\section{Setting}

The assessment was conducted in health centers within four regions of Ethiopia (Amhara, Oromia, Tigray, and South Nations Nationalities and Peoples') where USAID Transform: Primary Health Care Activity has been operating since January 2017. The Activity has divided the four regions into 29 clusters (10 in Oromia, 9 in Amhara, 6 in South Nations Nationalities and Peoples', and 4 in Tigray) which are constituted of zones and woredas with their primary hospitals, health centers and health posts. Health centers are a part of the primary health care of a three-tier health service delivery system of the country and serve as referral centers for cases from health posts and homes. Health centers provide basic emergency obstetric and newborn care (BEmONC) services and their maternity units are mainly run by midwives.

\section{Intervention}

One cluster per region was selected purposively as utilization of WHO SCC had not yet started at health centers of the selected clusters. A similar structured assessment tool was used for both pre and post intervention assessments where data on availability of essential childbirth supplies and adherence of health care providers to EBPs were collected.

In the modified checklist, some items of the original WHO SCC were removed while some were added, (Table 1). The original WHO SCC and the modified WHO SCC are found as supplementary files.

Based on the WHO SCC implementation guide, in September 2017, an orientation on the modified WHO SCC was conducted for data collectors and mentors (one regional officer per region and three to five cluster officers per cluster, who are master of public health degree holders with midwifery, nursing or public health officer backgrounds) and print outs of the checklist were distributed to the clusters. The cluster staff then conducted onsite orientations to health care providers (midwives and clinical nurses who had undergone two to four years of training), distributed the checklists, and collected pre intervention assessment data. The pre intervention data were collected by interviewing one 
Table 1 List of items removed and added to the original WHO SCC in the development of the modified, Ethiopian version checklist

\begin{tabular}{lll}
\hline $\begin{array}{l}\text { Pause points } \\
\text { (PP) }\end{array}$ & Items removed & Items added \\
\hline PP-1 & - & "Quick check performed?" \\
& & "Antiretroviral medicine?" \\
PP-2 & - & "Antiretroviral medicine?" \\
PP-3 & "Is mother bleeding abnormally?" & Components of essential newborn care. \\
& "Does the mother need to start, & List of both maternal and newborn danger signs. \\
& $\checkmark$ Antibiotics? & \\
& $\checkmark$ Magnesium sulfate and & \\
& antihypertensive?" & \\
"Confirm stay at facility for 24h after & "Refer mother to three postnatal visits (6-24 h, 3 days, 7 days) and an immunization visit \\
& $\begin{array}{l}\text { "Is mother's blood pressure normal?" } \\
\text { "Is baby feeding well?" }\end{array}$ & \\
\hline
\end{tabular}

health care provider per facility and directly observing the facility for presence of essential childbirth supplies. Regular, one-day mentoring visits were carried out every three months where all technical staff were mentored. The mentors used orientation materials prepared for the purpose (from the WHO SCC implementation guide), the WHO SCC implementation guide, and copies of the checklist to practice, discuss and fix technical and supply related gaps (if any). The post intervention assessment was conducted a year later using the same assessment tool and the same way of data collection as the one used at the pre intervention stage. Adherence to practices was assessed through interviews of providers by asking whether they carried out the EBPs mentioned in the modified WHO SCC or not, but a completed checklist was not considered as adherence to practice. Client records were reviewed to check for consistent and correct use of the checklist. (Fig. 1).

Data were cleaned, edited and entered to a data entry template with analysis being conducted using SPSS version 25. The availability of essential supplies and adherence of health care providers to essential birth practices were compared during the pre and post intervention stages using independent samples t-test and Levene's

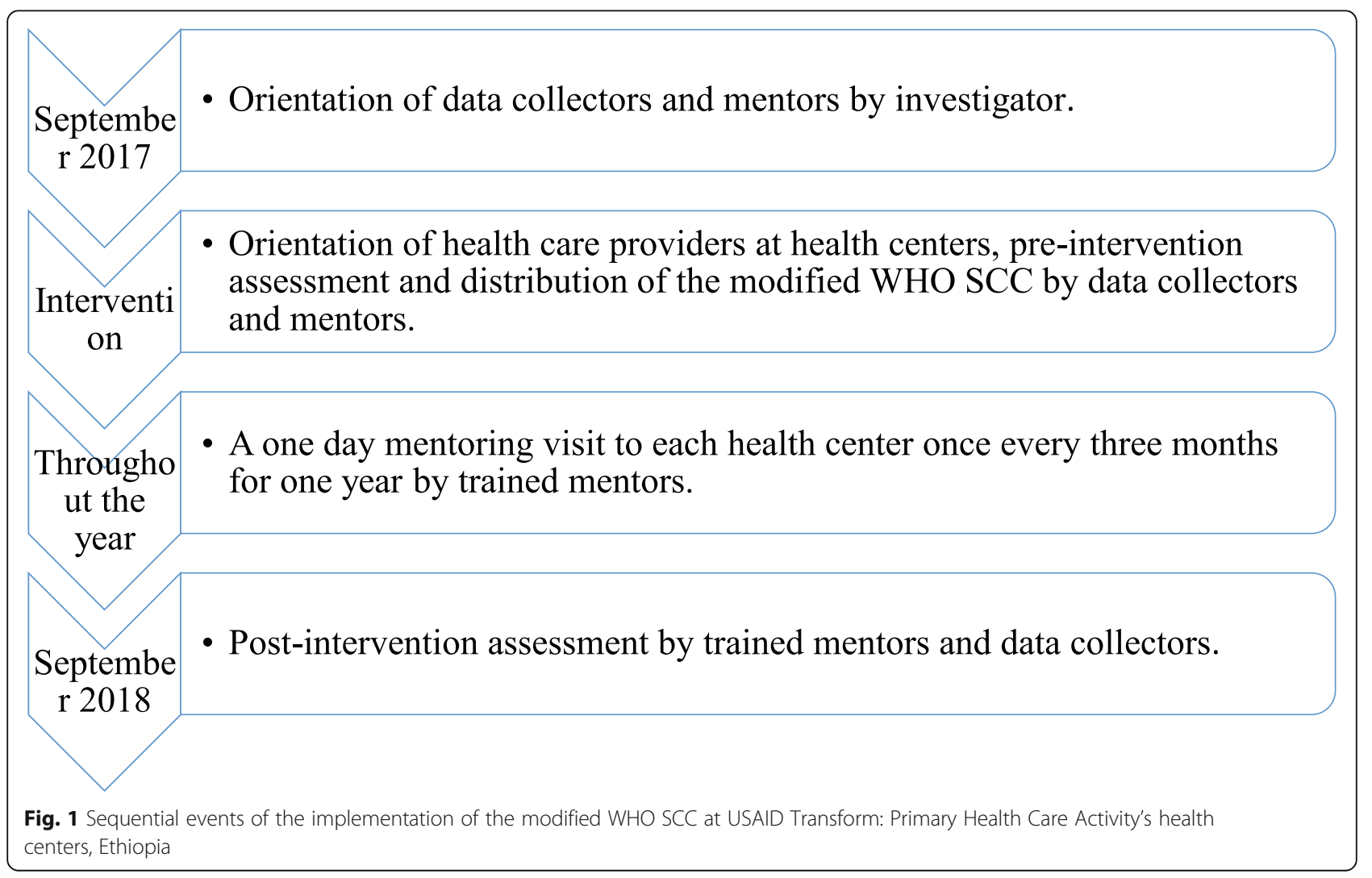


test, with the level of significance being determined at a $p<0.05$.

\section{Ethical considerations}

This assessment was conducted as part of USAID Transform: Primary Health Care Activity's interventions which is being implemented in Ethiopia under a cooperative agreement number of AID-663-A-17-00002.

\section{Results}

Data were collected from 247 and 187 health centers during the pre and post intervention periods, respectively.

Levene's test for equality of variances assessment revealed that homogeneity of variances was violated for all the variables except for pause point one, quick checks for danger signs performed before referral or admission of mothers, partograph use for all laboring mothers at the facility, and HIV testing and treatment services for both the mother and baby during antenatal care (ANC). Therefore, a Welch t-test was run to determine if there were differences in adherence of health care providers to EBPs between pre and post interventions and an independent-samples $t$-test was run for variables that met the homogeneity assumptions.

A statistically significant improvement from a pre intervention score of 63.6 to $83.5 \%$ post-intervention was observed in the availability of essential childbirth supplies in selected health centers of Ethiopia one year after the introduction of the modified WHO SCC, $t$ $(389.7)=-7.1, p=0.000$, (Table 2).
A statistically significant improvement in the adherence of health care providers to EBPs was observed post intervention which was one year after the introduction of the modified WHO SCC. The highest level of improvement was observed at pause point three $(26.2 \%, \mathrm{t}$ $(306.3)=-10.6, p=0.000)$ followed by pause point four $(21.1 \%, \mathrm{t}(282.5)=-8.0, \mathrm{p}=0.000)$ and pause point two $(18.2 \%, t(310.8)=-9.7, p=0.000)$. The least and statistically non-significant improvement was observed at pause point one $(3.3 \%, \mathrm{t}(432.0)=-1.5, p=0.131)$. (Table 3$)$.

\section{Discussion}

In this pre and post intervention study, changes in the availability of essential childbirth supplies in labor, delivery and postnatal care units, and adherence of health care providers to EBPs (which are known to have a high impact on reducing preventable maternal and neonatal deaths around the time of delivery) were assessed a year after the introduction of a modified version of the WHO SCC.

Statistically significant changes were observed in the availability of essential childbirth supplies in labor, delivery and postnatal care units a year after the introduction of the modified WHO SCC. The changes in the availability of essential childbirth supplies observed in this study are similar with the findings of another study conducted in Uttar Pradesh, India which is a comparable setup with where this study was conducted $[14,15]$.

The magnitude of increment in adherence of health care providers to EBPs from the pre to post intervention

Table 2 Pre and post modified WHO SCC intervention changes on the availability of essential childbirth supplies at selected health centers supported by USAID Transform: Primary Health Care Activity, Ethiopia

\begin{tabular}{|c|c|c|c|c|c|c|c|c|c|c|}
\hline & \multicolumn{3}{|c|}{ Before } & \multicolumn{3}{|l|}{ After } & \multirow{2}{*}{$\begin{array}{l}95 \% \mathrm{Cl} \text { for } \\
\text { Mean } \\
\text { Difference }\end{array}$} & \multirow[t]{2}{*}{$\mathbf{t}$} & \multirow[t]{2}{*}{ df } & \multirow[b]{2}{*}{$\mathbf{P}$} \\
\hline & M & SD & n & $\mathrm{M}$ & SD & $\mathbf{N}$ & & & & \\
\hline Availability of necessary supplies in labor, delivery and postnatal rooms & 63.6 & 33.0 & 247 & 83.5 & 22.5 & 150 & $-25.4,-14.4$ & $-7.1^{*}$ & 389.7 & 0.000 \\
\hline Oxytocin & 78.5 & 41.1 & 247 & 96.2 & 9.2 & 187 & $-23,-12.3$ & $-6.5^{*}$ & 278.3 & 0.000 \\
\hline Intravenous fluids & 76.1 & 42.7 & 247 & 96.6 & 6.3 & 187 & $-25.9,-15.0$ & $-7.4^{*}$ & 260.2 & 0.000 \\
\hline Antibiotics & 65.6 & 47.6 & 247 & 91.9 & 11.0 & 187 & $-32.5,-20.1$ & $-8.4^{*}$ & 280.2 & 0.000 \\
\hline Magnesium sulfate & 67.6 & 46.9 & 247 & 93.1 & 9.9 & 187 & $-31.6,-19.5$ & $-8.3^{*}$ & 274.4 & 0.000 \\
\hline Antiretroviral drugs & 50.6 & 50.1 & 247 & 80.1 & 19.4 & 187 & $-36.3,-22.6$ & $-8.4^{*}$ & 335.6 & 0.000 \\
\hline Vitamin K & 34.4 & 47.6 & 247 & 85.2 & 20.9 & 187 & $-57.4,-44.1$ & $15.0^{*}$ & 356.2 & 0.000 \\
\hline Tetracycline eye ointment & 59.1 & 49.3 & 247 & 88.9 & 13.7 & 187 & $-36.3,-23.3$ & $-9.1^{*}$ & 295.0 & 0.000 \\
\hline Bacillus Calmette-Guerin vaccine & 57.1 & 49.6 & 247 & 90.2 & 13.7 & 187 & $-39.7,-26.6$ & $10.0^{*}$ & 294.4 & 0.000 \\
\hline Oral Polio Vaccine & 72.5 & 44.8 & 247 & 94.4 & 8.3 & 187 & $-27.7,-16.2$ & $-7.5^{*}$ & 268.4 & 0.000 \\
\hline Gloves & 74.9 & 43.4 & 247 & 95.5 & 7.2 & 187 & $-26.1,-15.0$ & $-7.3^{*}$ & 263.9 & 0.000 \\
\hline Syringes & 77.3 & 42.0 & 247 & 95.7 & 6.8 & 187 & $-23.7,-13.0$ & $-6.8^{*}$ & 263.0 & 0.000 \\
\hline Soap & 63.6 & 48.2 & 247 & 92.3 & 11.2 & 187 & $-35,-22.5$ & $-9.0^{*}$ & 280.6 & 0.000 \\
\hline Water & 58.7 & 49.3 & 247 & 90.9 & 12.8 & 187 & $-38.6,-25.8$ & $-9.8^{*}$ & 288.6 & 0.000 \\
\hline Alcohol hand rub & 54.7 & 49.9 & 247 & 87.6 & 16.1 & 187 & $-39.6,-26.3$ & $-9.7^{*}$ & 310.7 & 0.000 \\
\hline
\end{tabular}

* $p<.05, M$ mean, $S D$ standard deviation, $C l$ Confidence interval, $d f$ degree of freedom, $n$ preintervention sample size, $N$ postintervention sample size 
Table 3 Pre and post modified WHO SCC intervention adherence of health care providers to essential birth practices at selected health centers supported by USAID Transform: Primary Health Care Activity, Ethiopia

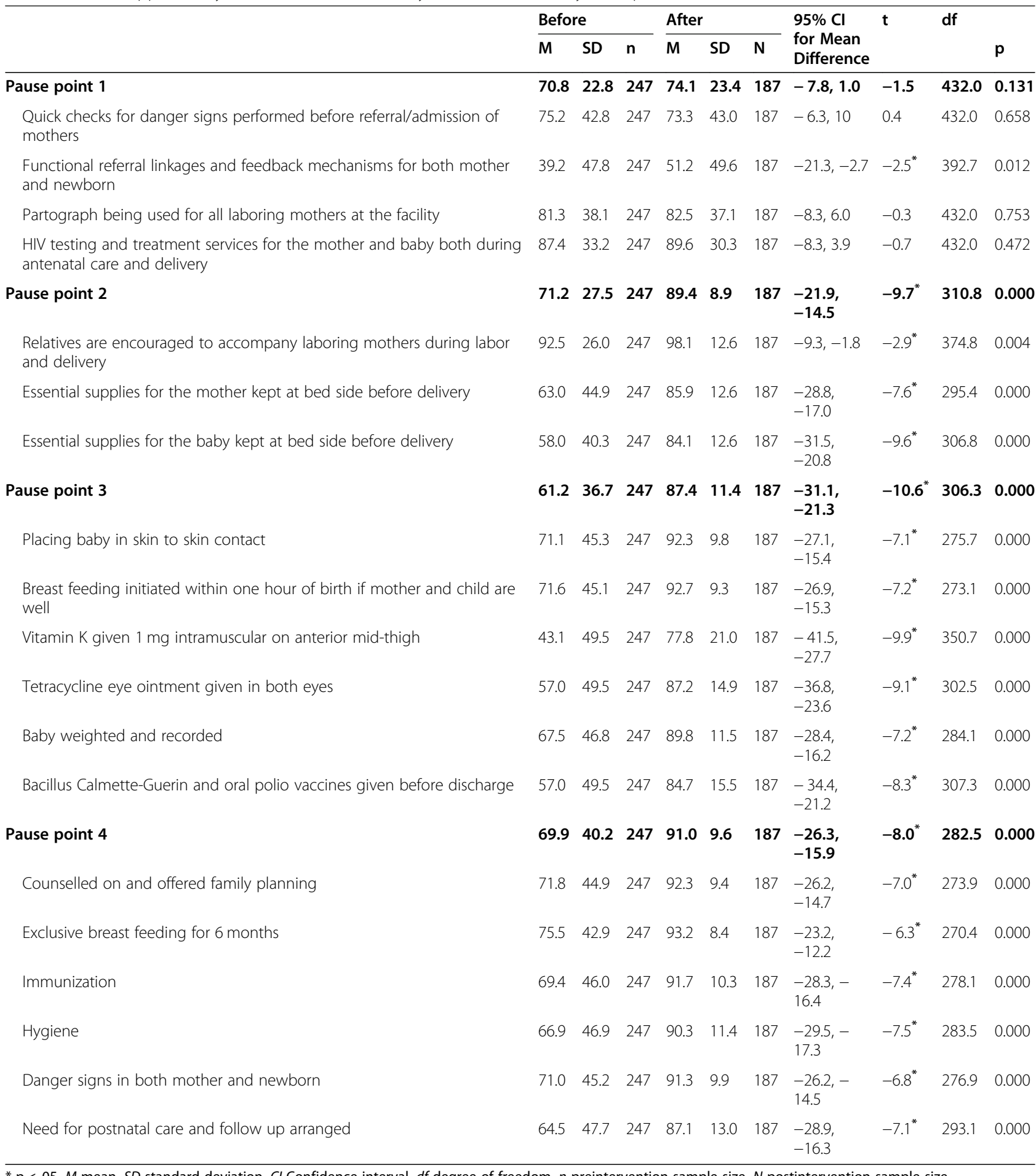

* $\mathrm{p}<.05, M$ mean, $S D$ standard deviation, $C l$ Confidence interval, $d f$ degree of freedom, $n$ preintervention sample size, $N$ postintervention sample size

was found to be similar with findings from studies at other similar settings of the world. A cluster randomized controlled trial in Uttar Pradesh, India, showed a similar improvement in adherence of health care providers to
EBPs in intervention groups as compared to control [12]. A study at Gobabis district hospital, Namibia, also showed an improvement of average EBPs delivered from 68 to $95 \%$ which is comparable with this study [10]. 
Similar improvements in adherence of health care providers to EBPs were reported in other studies conducted in Aceh, Indonesia, and Rajasthan, India [11, 13].

In contrast to this study, the highest increase in EBPs was at PP-4 in a Rwandan study which may be due to difference in the evaluation period where the Rwandan post intervention assessment was carried out three weeks after SCC introduction while this current study's post intervention assessment was carried out a year after introduction of the SCC [16].

Experience with a context-specific modified WHO SCC at two tertiary care settings in Sri Lanka showed that the mean adherence to the checklist practice was 52.7 and $32.2 \%$, both of which are lower than this study's findings. The difference in mean adherence can be explained by the difference in the settings where the studies were conducted. The Sri Lankan study used tertiary care centers where lack of staff numbers, lack of enthusiasm, inadequate training and advice on use of the checklist and lack of supervision from Ministry/institution levels were mentioned as reasons for low adherence. In contrast, this current study was conducted in primary care facilities where the health centers are not overwhelmed with cases and health care providers have adequate time to consistently and correctly use the checklist to guide their practices [17].

The average level of adherence of health care providers to checklist practices at another tertiary care center in Sri Lanka was found to be $71.3 \%$ which is comparable with the mean adherence at pause point one of this study. In addition to setting differences, increased workload, poor enthusiasm of health workers towards add on tasks to their routine schedules and level of userfriendliness of the checklist were mentioned in the Sri Lankan study as possible the reasons for the lower levels of adherence as compared to adherence at the other pause points of the current study [18].

Experience from 60 public health facilities in Uttar Pradesh, India, where improving adherence to EBPs using WHO SCC through peer coaching was conducted showed that 35 out of 39 (89.7\%) EBPs had achieved > $90 \%$ adherence in the presence of a coach by the final month of the eight month long intervention, as compared with only 7 out of 39 (18\%) practices during the first month. Despite the Hawthorne effect, the improvement in adherence to EBPs in the Indian study is comparable with the current study [19].

A research which aimed at testing a modified version of the WHO SCC in an Italian hospital showed that compliance to the checklist was high for midwives (96\%), but very low for obstetricians (3\%). The compliance of midwives in the Italian study is comparable with that of this current study but since there are no obstetricians working at health centers in Ethiopia a comparison cannot be made for that aspect of the study [20].

\section{Limitations}

The findings of this study should be interpreted with consideration to some of its limitations which are:

- The post intervention assessment was conducted on a lower number of health centers (187) as compared to the pre intervention facilities (247) due to inaccessibility of some of the health centers following security related issues at the time of data collection.

- The interviews might have not been conducted with same interviewees during the pre and post intervention assessments due to the high turnover rates of health care providers.

- Interviews with health care providers were used to assess adherence to essential birth practices with no direct observation of actual practices and it is possible that the checklists were simply filled out after delivery or at discharge and not in real time.

- As the study was conducted at primary care facilities where only mid-level providers (midwives, nurses, and public health officers) work, findings of the study may not be generalized for secondary and tertiary care facilities where a mix of various cadres of health work.

\section{Conclusion}

Improvements in availability of essential childbirth supplies at labor, delivery and postnatal care units and adherence of health care providers towards essential childbirth practices were observed a year after the introduction of a modified version of World Health Organization safe childbirth checklist at health centers of Ethiopia.

\section{Recommendations}

Scale up of the use of the modified World Health Organization safe childbirth checklist at all health facilities in the country is recommended. A local study on the contribution of the modified World Health Organization safe childbirth checklist on maternal and perinatal outcomes is also recommended.

\section{Supplementary Information}

The online version contains supplementary material available at https://doi. org/10.1186/s12884-021-03565-3.

\section{Additional file 1}

\section{Abbreviations}

AIDS: Acquired Immunodeficiency Syndrome; ANC: Antenatal Care; BEmONC: Basic Emergency Obstetric and Newborn Care; EBP: Essential Birth Practices; HIV: Human Immune Virus; PP: Pause Point; SCC: Safe Childbirth Checklist; SPSS: Statistical Package for Social Science Students; USAID: United States Agency for International Development; WHO: World Health Organization 


\section{Acknowledgements}

The authors would like to acknowledge USAID for funding the study, data collectors, mentors, health care providers, health facilities, clients whose records were utilized for research purposes, and the language editor of the manuscript.

\section{Authors' contributions}

HA was involved in the inception, data collection, analysis and interpretation, and write up of the manuscript. ZT was involved in the inception, data collection, reading and commenting of the final manuscript. IB was involved during analysis and interpretation of the data and commented on the final manuscript. TM, HM, ZM, ZG were involved during orientation and data collection stages and commented on the final manuscript. BD was involved in the inception and read and commented on the final manuscript. All authors have read and approved to the manuscript.

\section{Funding}

This study was fully funded by USAID as part of USAID Transform: Primary Health Care Activity in Ethiopia. The funding body had no role in the design, data collection, analysis, interpretation and writing stages of the study's undertakings.

\section{Availability of data and materials}

The datasets during and/or analyzed during this study are available from the corresponding author upon reasonable request.

\section{Ethics approval and consent to participate}

This assessment was conducted as part of the USAID Transform: Primary Health Care Activity which is being implemented in Ethiopia under a cooperative agreement number of AID-663-A-17-00002

\section{Consent for publication}

Consent for publication is not applicable in this research.

\section{Competing interests}

All authors declare that they do not have any competing interests.

Received: 21 April 2020 Accepted: 18 January 2021

Published online: 22 January 2021

\section{References}

1. Alkema L, Chou D, Hogan D, et al. Global, regional, and national levels and trends in maternal mortality between 1990 and 2015, with scenario-based projections to 2030: a systematic analysis by the UN maternal mortality estimation inter-agency group. Lancet. 2016;387(10017):462-74.

2. Conde-Agudelo A, Belizán JM, Lammers C. Maternal-perinatal morbidity and mortality associated with adolescent pregnancy in Latin America: crosssectional study. Am J Obstet Gynecol. 2005:192(2):342-9.

3. Patton GC, Coffey C, Sawyer SM, et al. Global patterns of mortality in young people: a systematic analysis of population health data. Lancet. 2009; 374(9693):881-92.

4. Say L, Chou D, Gemmill A, et al. Global causes of maternal death: a WHO systematic analysis. Lancet Glob Health. 2014;2(6):e323-e33.

5. You D, Hug L, Ejdemyr S, et al. Global, regional, and national levels and trends in under-5 mortality between 1990 and 2015, with scenario-based projections to 2030: a systematic analysis by the UN inter-agency Group for Child Mortality Estimation. Lancet. 2015;386(10010):2275-86.

6. Kanclerz P, Grzybowski A, Tuuminen R. Is it time to consider glaucoma screening cost-effective? Lancet Glob Health. 2019:7(11):e1490.

7. Lee SH, Nurmatov UB, Nwaru BI, Mukherjee M, Grant L, Pagliari C. Effectiveness of mHealth interventions for maternal, newborn and child health in low-and middle-income countries: systematic review and metaanalysis. J Glob Health. 2016;6(1):010401.

8. Spector JM, Agrawal P, Kodkany B, et al. Improving quality of care for maternal and newborn health: prospective pilot study of the WHO safe childbirth checklist program. PloS one. 2012;7(5).

9. Funk KM, Axelrod S. A Review of:"Gawande, A.(2009). The Checklist Manifesto-How to Get Things Right.", vol. 209. New York: Metropolitan Books, Taylor \& Francis; 2011

10. Kabongo L, Gass J, Kivondo B, et al. Implementing the WHO safe childbirth checklist: lessons learnt on a quality improvement initiative to improve mother and newborn care at Gobabis District hospital, Namibia BMJ Open Qual 2017:6: e000145.

11. Kumar S, Yadav V, Balasubramaniam S, et al. Effectiveness of the WHO SCC on improving adherence to essential practices during childbirth, in resource constrained settings. BMC Pregnancy Childbirth. 2016;16:345.

12. Semrau KE, Hirschhorn LR, Marx Delaney M, BetterBirth Trial Group, et al. Outcomes of a coaching-based WHO safe childbirth checklist program in India. N Engl J Med. 2017;377(24):231324.

13. Doria S, Diba F, Susanti SS, Vollmer S, Monfared IG. Mothers' experiences of quality of care and potential benefits of implementing the WHO safe childbirth checklist: a case study of Aceh Indonesia. BMC Pregnancy Childbirth. 2019;19:461.

14. Galvin $G$, Hirschhorn $L R$, Shaikh M, et al. Availability of safe childbirth supplies in 284 facilities in Uttar Pradesh. Matern Child Health J. 2019;23: 240-9.

15. Maisonneuve JJ, Semrau KEA, Maji P, et al. Effectiveness of a WHO safe childbirth checklist coaching-based intervention on the availability of essential birth supplies in Uttar Pradesh, India. Int J Qual Health Care. 2018; 30(10):769-77.

16. Tuyishime E, Park PH, Rouleau D, Livingston P, Banguti PR, Wong R. Implementing the World Health Organization safe childbirth checklist in a district Hospital in Rwanda: a pre-and post-intervention study. Matern Health, Neonatol Perinatol. 2018;4(1):7.

17. Senanayake HM, Patabendige M, Ramachandran R. Experience with a context-specific modified WHO safe childbirth checklist at two tertiary care settings in Sri Lanka. BMC Pregnancy Childbirth. 2018:18:411.

18. Patabendige M, Senanayake H. Implementation of the WHO safe childbirth checklist program at a tertiary care setting in Sri Lanka: a developing country experience. BMC Pregnancy Childbirth. 2015;15:12.

19. Delaney MM, Maji P, Kalita T, et al. Improving adherence to essential birth practices using the WHO safe childbirth checklist with peer coaching: experience from 60 public health facilities in Uttar Pradesh. Glob Health: Sci Pract. 2017;5(2):217-31

20. Albolino S, Dagliana G, Illiano D, et al. Safety and quality in maternal and neonatal care: the introduction of the modified WHO Safe Childbirth Checklist. Ergonomics. 2018;61(1):185-93.

\section{Publisher's Note}

Springer Nature remains neutral with regard to jurisdictional claims in published maps and institutional affiliations.

Ready to submit your research? Choose BMC and benefit from:

- fast, convenient online submission

- thorough peer review by experienced researchers in your field

- rapid publication on acceptance

- support for research data, including large and complex data types

- gold Open Access which fosters wider collaboration and increased citations

- maximum visibility for your research: over $100 \mathrm{M}$ website views per year

At $\mathrm{BMC}$, research is always in progress.

Learn more biomedcentral.com/submission 